\title{
Public Willingness to Participate in COVID-19 Vaccine Clinical Trials: A Study from Jordan
}

This article was published in the following Dove Press journal:

Patient Preference and Adherence

\author{
Rana K Abu-Farha $\mathbb{D}^{\prime}$ \\ Karem H Alzoubi $\mathbb{D D}^{2}$ \\ Omar F Khabour (D) ${ }^{3}$ \\ 'Department of Clinical Pharmacy and \\ Therapeutics, Faculty of Pharmacy, \\ Applied Science Private University, \\ Amman, Jordan; ${ }^{2}$ Department of Clinical \\ Pharmacy, Jordan University of Science \\ and Technology, Irbid 22II0, Jordan; \\ ${ }^{3}$ Department of Medical Laboratory \\ Sciences, Jordan University of Science and \\ Technology, Irbid 22 I I0, Jordan
}

Correspondence: Rana K Abu-Farha Department of Clinical Pharmacy and Therapeutics, Faculty of Pharmacy, Applied Science Private University, Amman II93I, Jordan

Tel +96265609957 ext | 496

Fax +9625232899

Email abufarharana@yahoo.com
Purpose: The development and production of novel vaccine to prevent COVID-19 is an international imperative to human lives. For that purpose, clinical trials have to be carried out as per international ethical standards. The current study was undertaken to examine the willingness to participate in COVID-19 vaccine clinical trials and to determine factors that might affect their decision to participate.

Patients and Methods: A cross-sectional survey study was carried out among the public in Jordan. During the study period, a convenience sample of adults (aged 18 years or above) were asked to participate via an online self-administered survey that was designed to evaluate the willingness to participate in COVID-19 vaccine clinical trials and to determine factors affecting their decision to participate.

Results: Results showed that, among participants ( $\mathrm{n}=1,287), 36.1 \%$ reported to be willing to participate in clinical trials of the vaccine. Additionally, a lower percentage $(18.1 \%)$ were willing to allow their children to participate. Motivators that encourage participation were the desire to return to normal life $(73.2 \%)$, followed by the desire to help in finding a treatment for COVID-19 infection (68.1\%). Barriers towards the participation were not wanting to be challenged by the virus $(54.7 \%)$, fear $(40.7 \%)$, lack of time $(40.4 \%)$, and mistrust in pharmaceutical companies $(38.9 \%)$. Finally, results showed that higher educational level was associated with lower willingness to participate $(P=0.001)$, whereas having a previous participation in clinical studies is associated with a significantly higher willingness to participate in COVID-19 vaccine clinical trials $(P<0.001)$.

Conclusion: A good portion of Jordanians are positive regarding participation in clinical studies of COVID-19 vaccine. Educational level and previous participation in clinical studies were among the determinants of such willingness. In addition, fear and lack of time were among the barriers of participation.

Keywords: willingness, COVID-19, clinical trials, participation, Jordan

\section{Introduction}

After the initial outbreak of the severe acute respiratory syndrome coronavirus 2 (SARS-CoV-2) in Wuhan, Hubei province in China, the SARS-CoV-2 started into speared worldwide to more than 213 countries and territories, and hundreds of thousands of victims have been reported. ${ }^{1}$ The human population is considered SARS-CoV-2 naïve, ${ }^{2}$ which puts humanity at greater risk of increased morbidity and mortality, and it may negatively affect the economy in many countries. $^{3}$ Therefore, the current spread of this virus has stressed the urgent need for the emergence of preventive measure in order to reduce and limit the accelerated spread of this virus and burdens of the pandemic. ${ }^{4}$ Among the 
preventive measures that have been undertaken by several countries worldwide are the execution of suppression strategies such as quarantine and isolation, ${ }^{5}$ the use of medical face masks, ${ }^{6}$ as well as the implementation of social distancing, ${ }^{7}$ which contributed to some extent in reducing the speed of the pandemic. ${ }^{5,7}$

The development of a new and novel COVID-19 vaccine is considered an urgent need, and each novel vaccine needs to be evaluated in humans for its safety, efficacy, and immunogenicity before obtaining a license to be used. ${ }^{9}$ Regulatory agencies classify clinical trials to develop a novel vaccine into four different phases that are governed by strict regulation. During the first phase (phase I), the new vaccine is tested on a small healthy group of people which may not represent the target population. ${ }^{10}$ Then, the number of subjects will be expanded during the next phase (phase II), where the vaccine is tested on a larger group of hundreds to thousands of subjects with a characteristic similar to that for whom the novel vaccine is intended to be used. $^{10}$ Within the third phase (phase III), the novel vaccine is tested on a few thousand subjects from the target population for efficacy and safety evaluation. ${ }^{10}$ Finally, following vaccine licensure, postmarketing surveillance (phase IV studies) will be conducted to monitor the efficacy of the vaccine in the large target population and to detect any possible non-detected adverse reactions. ${ }^{10}$

Unfortunately, subjects' hesitancy and refusal to participate in vaccine clinical trials may be considered a major barrier for the development of a COVID-19 vaccine in the future and in reaching herd immunity. ${ }^{11}$ Factors that may contribute to hesitancy in participation in vaccine clinical trials may include fear and mistrust, and lack of knowledge about clinical trials. ${ }^{12}$ Participation in the vaccine clinical study might be also affected by the COVID-19 epidemiological situation in the country. As of November 3, 2020, Jordan reported 81,743 COVID-19 cases and a total of 913 deaths. Currently, to our knowledge, there are few studies that have evaluated public willingness to participate in COVID-19 clinical trials. ${ }^{13-15}$ Accordingly, the current investigation was conducted to evaluate the willingness of the Jordanian public to participate in COVID-19 vaccine clinical trials and to determine factors that might affect their decision to participate. Knowing such factors may provide a guide for the pharmaceutical companies to improve the recruitment of subjects in such clinical trials.

\section{Methods}

This was a cross-sectional study conducted during the first half of 2020 among the public in various cities of Jordan. The sampling method was a convenience sample. Adults (aged 18 years or above) were asked to participate via an online self-administered survey that was distributed using social media platforms (Facebook and WhatsApp). Before enrolment, potential participants were taken to a page that provided them with a detailed explanation about the purpose of the study and then were asked to agree to a compulsory electronic informed consent form that included statements about voluntary participation and anonymity of the survey. The study was approved by the Institutional Review Board of Jordan University of Science and Technology (Approval code: 23/128/2019), and the World Medical Association Declaration of Helsinki guidance was followed. ${ }^{16}$

The questionnaire of this study (Supplementary mate rial) was based on a broad literature search using a variety of databases including Medline/PubMed, and Google Scholar. Thus, relevant literature related to the public perception to participation in vaccine clinical trials was identified. The questions included in the questionnaire were built based on reviewed literature with some modification. ${ }^{13}$ Content as well as face validations were carried out. First, a group of experts provided feedback on the items of the survey, where it was modified as per their comments. Next, the modified draft of the survey went through pilot testing on 30 participants to provide feedback about the clarity and comprehensibility of the items of the survey.

The finalized version of the survey tool had three sections: A) Part 1 included demographic characteristics and the medical history of participants. B) Part 2 examined participants' previous experiences in relation to COVID19. In this section, participants were asked if they knew a person who had been infected/died from COVID-19. Participants were also asked to assess their fear level of COVID-19 infection, and their perceived risk of being infected. Fear level was self-assessed on a 1-5 scale. C) The last part of the questionnaire evaluated attitude toward enrolment in a COVID-19 vaccine clinical trial and motivators and barriers related to this participation. 
The statistical package for social science (SPSS ${ }^{\circledR}$ ) version 22 (SPSS $^{\circledR}$ Inc., Chicago, IL, USA) was used for data analysis. The mean $\pm \mathrm{SD}$ and percentages were used for continuous and categorical variables, respectively. Normality was checked using the Shapiro-Wilk test. Univariate and multivariate logistic regression were used to screen for factors that affect the willingness of participants to enroll in clinical trials of potential COVID-19 vaccine. Variables that were found to be significant on a single predictor level $(P$-value $<0.25)$ using univariate logistic regression analysis were entered into multiple logistic regression analysis. In the multiple logistic regression analysis, variables that were independently associated with the willingness of participants to enroll in clinical trials of potential COVID-19 vaccine were identified. Statistical significance was considered at a $P$-value $<0.05$, and power of 0.9 .

\section{Results}

In total, 1,287 participants were recruited in this study. Participants had a mean age of 30.1 (9.7) years (Table 1).

Table I Demographic Characteristics of the Study Sample at Baseline $(\mathrm{N}=\mathrm{I}, 287)$

\begin{tabular}{|c|c|c|}
\hline Parameters & Mean (SD) & n (\%) \\
\hline Age (years) & 30.1 (9.7) & \\
\hline $\begin{array}{l}\text { Gender } \\
\text { - Female } \\
\text { - Male }\end{array}$ & & $\begin{array}{l}734(57.0) \\
553(53.0)\end{array}$ \\
\hline $\begin{array}{l}\text { Educational level } \\
\text { - Low (school level or lower) } \\
\text { - High (University or higher) }\end{array}$ & & $\begin{array}{l}394(30.6) \\
893(69.4)\end{array}$ \\
\hline $\begin{array}{l}\text { Marital status, n (\%) } \\
\text { - Married } \\
\text { - Not married (single, divorced, widowed) }\end{array}$ & & $\begin{array}{l}619(48.1) \\
668(51.9)\end{array}$ \\
\hline $\begin{array}{l}\text { Nationality } \\
\text { - Jordanian } \\
\text { - Other }\end{array}$ & & $\begin{array}{l}1229(95.5) \\
58(4.5)\end{array}$ \\
\hline $\begin{array}{l}\text { Place of residence } \\
\text { - South Jordan } \\
\text { - Middle Jordan } \\
\text { - North Jordan }\end{array}$ & & $\begin{array}{l}42(3.3) \\
193(15.0) \\
1052(81.7)\end{array}$ \\
\hline $\begin{array}{l}\text { Do you have a biomedicine-related degree? } \\
\text { - Yes } \\
\text { - No }\end{array}$ & & $\begin{array}{l}168(13.1) \\
1119(86.9)\end{array}$ \\
\hline $\begin{array}{l}\text { Have you ever participated in a clinical study? } \\
\text { - Yes } \\
\text { - No }\end{array}$ & & $\begin{array}{l}109(8.5) \\
1178(91.5)\end{array}$ \\
\hline
\end{tabular}

Around half of the subjects were female ( $\mathrm{n}=734,57.0 \%)$ and were married $(\mathrm{n}=619,48.1 \%)$. Around two-thirds of them has a graduate or postgraduate degree $(n=893$, 69.4\%), with few of them having a biomedical related degree $(n=168,13.1 \%)$. Most of the recruited subjects were Jordanian $(\mathrm{n}=1,229,95.5 \%)$, and living in north Jordan ( $\mathrm{n}=1,052,81.7 \%)$. Only a few participants reported to volunteer in a previous clinical study $(\mathrm{n}=109,8.5 \%)$.

When the general health of the participants was assessed (Figure 1), most of them reported to have either an excellent $(n=665,51.7 \%)$ or good health status $(n=611$, $47.5 \%)$. The majority of participants reported no chronic co-morbidity $(\mathrm{n}=1,169,90.8 \%)$, and around $57 \%$ reported to receive a previous vaccine as a protection against seasonal influenza $(\mathrm{n}=739,57.4 \%)$.

Among the recruited subjects, around $10 \%$ of them knew someone who have been infected and diagnosed with COVID-19 ( $\mathrm{n}=127,9.9 \%)$. Only 34 subjects reported to know someone who died from COVID-19 (2.6\%). Participants have reported their rate of fear of COVID-19, and around 9\% reported to have a high fear of the infection $(n=112,8.7 \%)$. Regarding participant perception to catch the infection, only $5.8 \%$ of them believed to be at risk of catching the infection (refer to Table 2).

Regarding participants' attitude to enroll in a COVID-19 vaccine clinical trial (Figure 2), responses demonstrated that $36.1 \%$ of participants $(n=465)$ reported to be willing to participate, while the remaining $63.9 \%(\mathrm{n}=822)$ either refused or were not sure. Also, a lower percentage of participants $(n=214,16.6 \%)$ will permit their children to enroll in such a clinical trial if they were parents.

Motivators that encourage the participants to enroll in the vaccine clinical trial are shown in Figure 3. Participants' desire to return to normal life was the biggest motivator for them to participate in such a clinical trial ( $\mathrm{n}=942,73.2 \%$ ), followed by their desire to help in finding a treatment for COVID-19 infection $(\mathrm{n}=867$, $68.1 \%)$. On the other hand, only $32.9 \%(n=423)$ may participate to get a personal benefit, such as receiving compensation.

The barriers to enroll in the vaccine clinical trial were assessed using six statements (Figure 4). More than half of the participants reported that they do not want to be challenged by the virus $(\mathrm{n}=704,54.7 \%)$, and around $40.7 \%(\mathrm{n}=524)$ revealed that the have a strong fear of the virus. Also, $40.4 \%$ of them $(n=520)$ reported that they do 


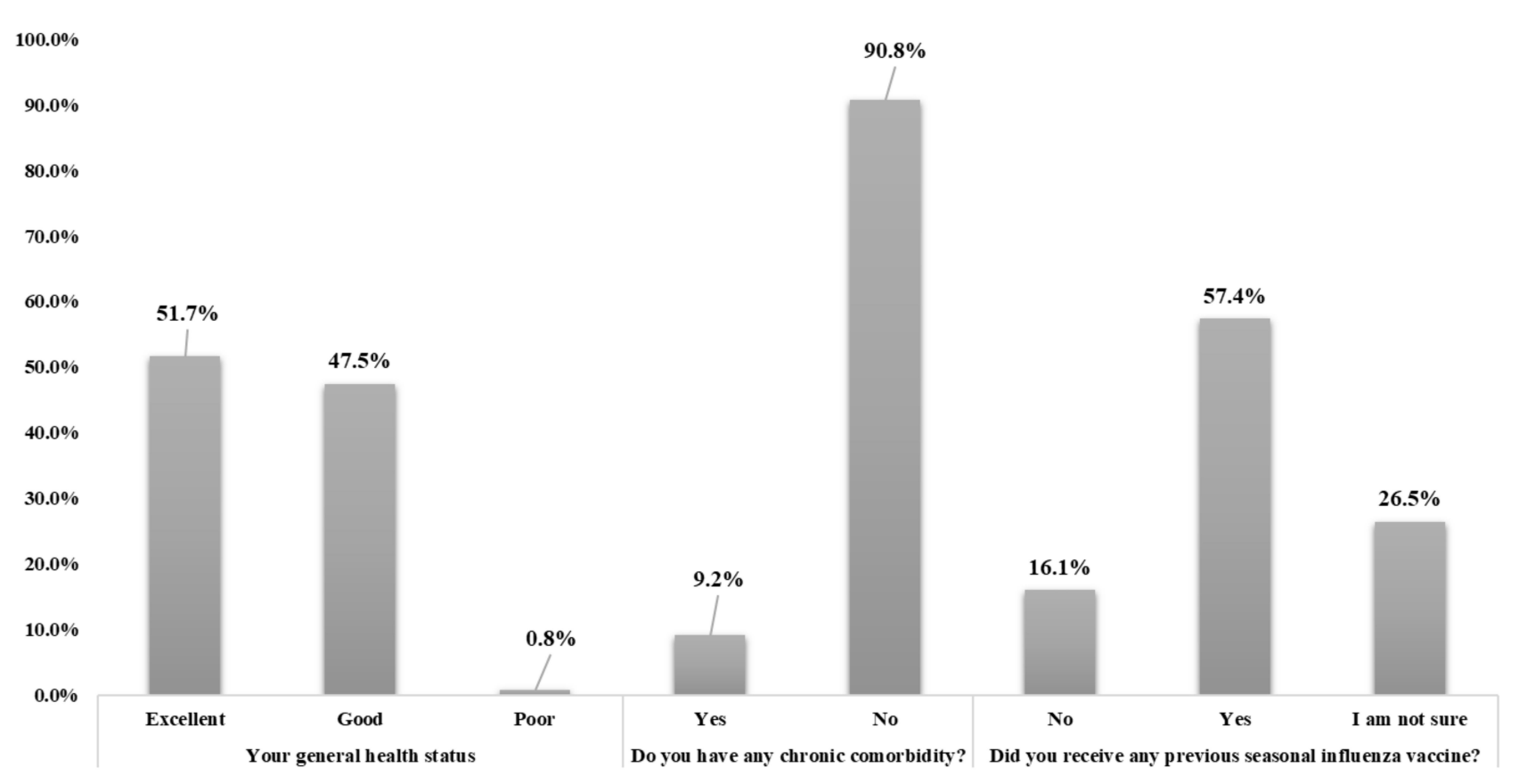

Figure I Study participant medical and health status $(n=I, 287)$.

not have time to participate in such trials, while $38.9 \%$ of them $(\mathrm{n}=501)$ do not trust pharmaceutical companies.

Finally, results showed that having a higher educational level resulted in a significantly lower attitude to enroll in

Table 2 Participants' Experience with COVID-19 Infection $(\mathrm{N}=\mathrm{I}, 287)$

\begin{tabular}{|c|c|}
\hline Questions & n (\%) \\
\hline $\begin{array}{l}\text { Has someone you know been infected and diagnosed } \\
\text { with COVID-19? } \\
\text { - Yes } \\
\text { - No }\end{array}$ & $\begin{array}{l}127(9.9) \\
\mathrm{I}, \mathrm{I} 60(90.1)\end{array}$ \\
\hline $\begin{array}{l}\text { Has someone you know died with COVID-I9? } \\
\text { - Yes } \\
\text { - No }\end{array}$ & $\begin{array}{l}34(2.6) \\
I, 253(97.4)\end{array}$ \\
\hline 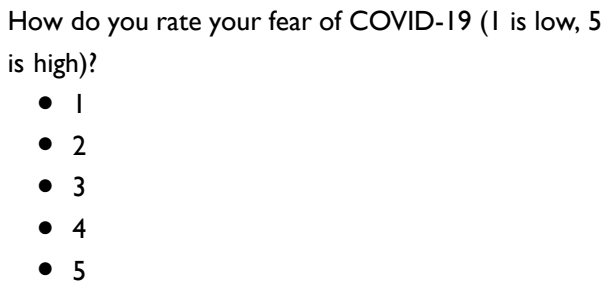 & $\begin{array}{l}401(31.2) \\
270(21.0) \\
382(29.7) \\
122(7.5) \\
112(8.7)\end{array}$ \\
\hline $\begin{array}{l}\text { Do you think that you have perceived individual risk } \\
\text { to catch COVID-19? } \\
\text { - Yes } \\
\text { - No } \\
\text { - I am not sure }\end{array}$ & $\begin{array}{l}75(5.8) \\
777(60.4) \\
435(33.4)\end{array}$ \\
\hline
\end{tabular}

vaccine clinical trials (Table $3, P=0.001$ ), while having a previous participation in any clinical studies is associated with a significantly higher attitude to enroll in vaccine clinical trials $(P<0.001)$.

\section{Discussion}

In the current study, the willingness of Jordanians toward participation in a clinical trial of COVID-19 vaccinations was investigated. Results showed that a fair portion of participants $(36.1 \%)$ reported willingness to participate in clinical trials of the vaccine.

The COVID-19 disease continues to spread with daily increase in the reported cases and deaths from countries overall the globe. ${ }^{1,17}$ Although some advances in both pharmaceutical and clinical management interventions have been achieved, ${ }^{18}$ the world pins its hopes on vaccines to prevent COVID-19. Before it is delivered to the market, COVID-19 vaccines need to be evaluated in humans for its safety, efficacy, and immunogenicity. ${ }^{9,19-21}$ This requires conduction of international clinical trials and recruitments of subjects from different countries to cover most of the populations' backgrounds. ${ }^{22,23}$ Among the suggested obstacles of the conduction of COVID-19 clinical trials is hesitancy to participate in such studies. ${ }^{24}$ The present findings reported the willingness of Jordanians to participate in the clinical trials of 


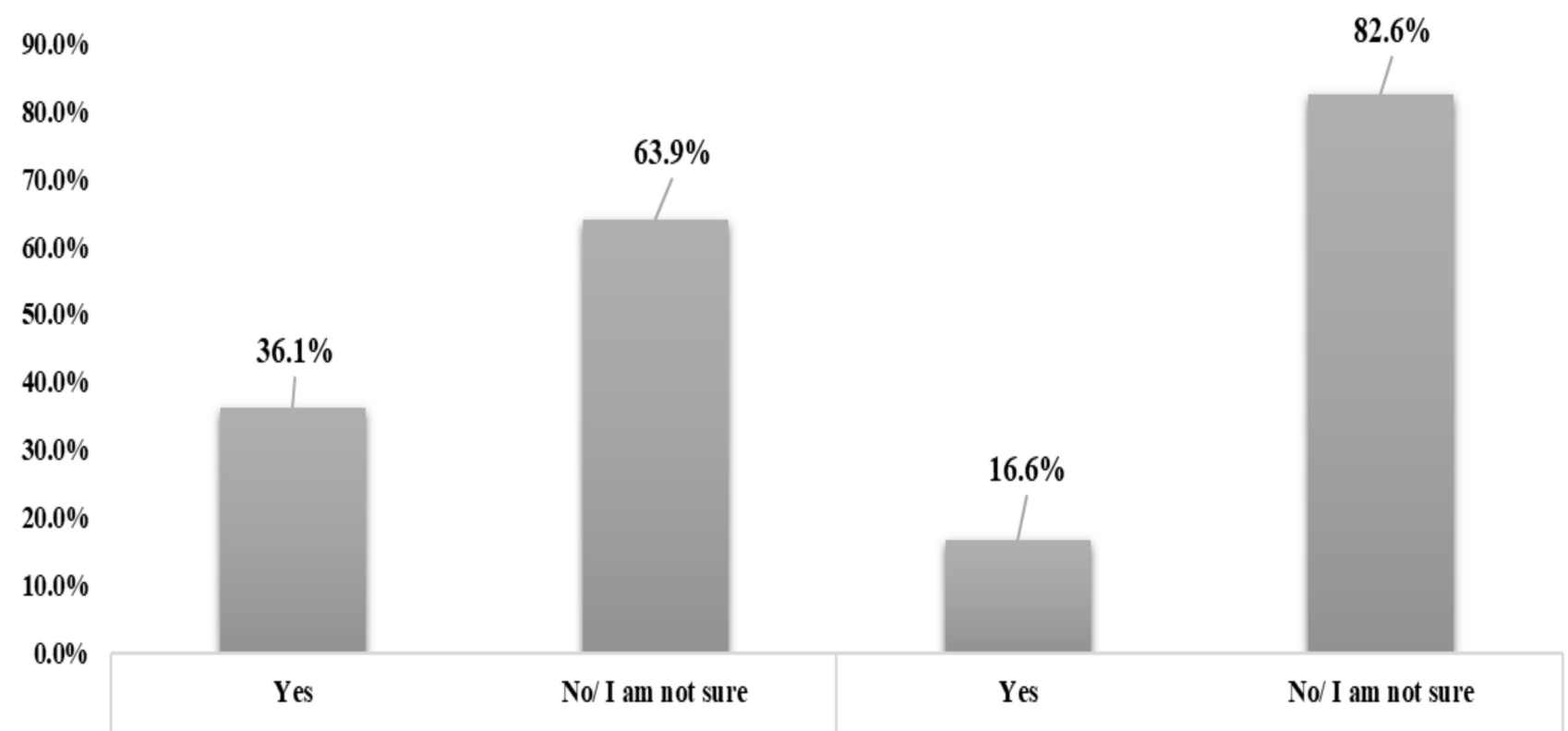

Are you willing to participate in COVID-19 vaccine clinical trials? If you are a parent, are you willing to let your child to participate in COVID-19 vaccine clinical trial?

Figure 2 Participants' willingness to participate in COVID-19 vaccine clinical trials $(n=1,287)$.

\section{I might receive good compensation for $\mathrm{my}$ participation}

\section{I have relativ es $w$ ith chronic diseases that might $d$ ie if $r$ accine $w$ as not der eloped}

\section{Vaccine might hav e p op ulation sp ecific sid e effects and should be tested in Jordan}

\section{To return to normal life}

\section{To help find ing treatment to COVID-19}

$32.9 \%$

$43.4 \%$

\section{$54.9 \%$}

\section{$73.2 \%$}

\section{$68.1 \%$}

\section{$\begin{array}{llllll}0.0 \% & 20.0 \% & 40.0 \% & 60.0 \% & 80.0 \% & 100.0 \%\end{array}$}

Figure 3 Motivators for the participation in COVID-I9 vaccine clinical trials as perceived by the study participants $(n=I, 287)$.

COVID-19 vaccine, where $36.1 \%$ of participants were willing to participate. Good interest in the participation of COVID-19 vaccine clinical trials was reported in studies that were conducted in Wuhan, China and in France. ${ }^{13,15}$ The percentage of Jordanians who are willing to enroll in COVID-19 vaccine clinical trials is slightly lower than that reported in a previous study conducted in France which examined the willingness to participate in COVID-19 vaccine clinical trials. ${ }^{13}$ The current study also found that men were more willing to 


\section{No need to conduct such studies in Jord an as the virus sp read is under control}

I don't have the time to participate

My health status does not permit me to participate

I have strong fear from the virus

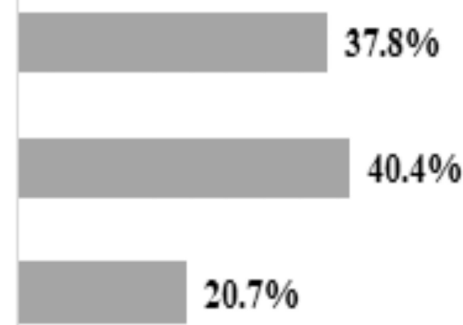

$40.7 \%$
I don't trust pharmaceutical companies

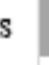

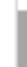

I don't want to be challenged with the rirus

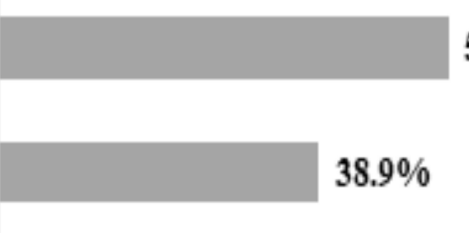

$0.0 \% \quad 20.0 \% \quad 40.0 \%-60.0 \%$
$54.7 \%$

$80.0 \% \quad 100.0 \%$

Figure 4 Barriers against the participation in COVID-19 vaccine clinical trials as perceived by the study participants $(n=I, 287)$.

participate than women in COVID-19 clinical trials. This is consistent with a study conducted in Wuhan, China. $^{15}$

Among the barriers to enroll in COVID-19 vaccine clinical trials reported in the current study were avoiding to be challenged by the virus, fear of the virus, no time to participate, and lack of trust in pharmaceutical companies. A previous study suggested to speed-up the process of COVID-19 vaccine development, the time of clinical phases II and III can be reduced by using human challenge studies through deliberate infection of healthy volunteers with the virus after administration of the tested vaccine. $^{25,26}$ This might increase the fear of volunteers and thus the willingness to participate in the clinical trials, as shown by the current study findings. However, speeding the development of the vaccine for the purpose of saving human lives could be ethically justified. ${ }^{27}$ Speeding the development of the vaccine should rely on the expected social value, which might not be realistic in the current political moment. ${ }^{28}$ Among the reported barriers in the current study are lack of time, mistrust, and fear. These barriers are common ones that prevent participation in clinical studies in general. ${ }^{29-32}$ For example, a study that was conducted among rural and urban communities showed that fear, side-effects, limited understanding, limited time, and mistrust were common barriers that prevented participation in clinical studies. ${ }^{33}$ According to study findings, willingness to be enrolled in COVID-19 vaccine clinical trials was associated with educational level and participation in a previous clinical study. Participants with a higher level of education are less prone to enroll in a clinical trial than the ones with a low level of education. It is possible that educated people are more aware about the procedures of clinical studies and the time/efforts needed when enrolling in such studies and, thus, are more hesitant to volunteer. In addition, it is expected that educated people are more aware about the seriousness of COVID-19 and therefore would like to avoid to be challenged by the virus. In a study that was conducted in South Carolina, lacking knowledge and understanding about clinical studies and literacy rate were found to be associated with willingness to participate in clinical trials. ${ }^{34}$ The barriers of the participation in COVID-19 vaccine clinical trials reported in the current investigation should be addressed in future recruitment of participants to enhance the rate of participation.

Among the study limitations is the sampling approach, which depends on the accessibility of subjects to internetbased services and their willingness to participate in online-based survey studies. In addition, the study was conducted purely on the Jordanian population and, thus, the study findings might not apply to other populations in the region and the world. Therefore, additional confirmation studies are needed in the future. 
Table 3 Assessment of Factors Affecting Participants' Willingness to Participate in COVID-19 Vaccine Clinical Trials $(\mathrm{N}=\mathrm{I}, 287)$

\begin{tabular}{|c|c|c|c|c|}
\hline \multirow[t]{2}{*}{ Parameters } & \multicolumn{4}{|c|}{$\begin{array}{l}\text { Willingness to Participate [0: No } \\
(n=465) \text {, I: Yes }(n=822)]\end{array}$} \\
\hline & OR & $P$-value\# & OR & $\begin{array}{l}P \text {-value } \\
\$\end{array}$ \\
\hline Age (years) & 0.999 & 0.880 & - & - \\
\hline $\begin{array}{l}\text { Gender } \\
\text { - Female } \\
\text { - Male }\end{array}$ & $\begin{array}{l}\text { Reference } \\
\text { I.354 }\end{array}$ & $0.011 *$ & 1.133 & 0.329 \\
\hline $\begin{array}{l}\text { Educational level } \\
\text { - Low (school level or } \\
\text { lower) } \\
\text { - High (University of } \\
\text { higher) }\end{array}$ & $\begin{array}{l}\text { Reference } \\
0.638\end{array}$ & $<0.001 *$ & 0.658 & $0.00 I^{* *}$ \\
\hline $\begin{array}{l}\text { Marital status, n (\%) } \\
\text { - Married } \\
\text { - Not married (single, } \\
\text { divorced, widowed) }\end{array}$ & $\begin{array}{l}\text { Reference } \\
1.030\end{array}$ & 0.801 & - & - \\
\hline $\begin{array}{l}\text { Place of residence } \\
\text { - North Jordan } \\
\text { - Other }\end{array}$ & $\begin{array}{l}\text { Reference } \\
0.940\end{array}$ & 0.682 & - & - \\
\hline $\begin{array}{l}\text { Nationality } \\
\text { - Jordanian } \\
\text { - Others }\end{array}$ & $\begin{array}{l}\text { Reference } \\
0.790\end{array}$ & 0.416 & - & - \\
\hline $\begin{array}{l}\text { Do you have a biomedicine- } \\
\text { related degree? } \\
\text { - No } \\
\text { - Yes }\end{array}$ & $\begin{array}{l}\text { Reference } \\
1.314\end{array}$ & $0.105^{*}$ & 1.128 & 0.511 \\
\hline $\begin{array}{l}\text { Have you ever participated } \\
\text { in a clinical study? } \\
\text { - No } \\
\text { - Yes }\end{array}$ & $\begin{array}{l}\text { Reference } \\
4.918\end{array}$ & $<0.001 *$ & 4.738 & $<0.001^{* *}$ \\
\hline
\end{tabular}

Notes: \#Using simple logistic regression, \$using multiple logistic regression, *eligible for entry to multiple logistic regression, **significant at 0.05 significance level.

In conclusion, a fair portion of the Jordanians are willing to participate in clinical studies of COVID-19 vaccine. Educational level and previous participation in clinical studies were among the determinants of such willingness. Understanding of factors and barriers that are associated with willingness to participate in COVID-19 vaccine clinical trials can facilitate the recruitment of the volunteers.

\section{Acknowledgment}

This project was carried out as part of "The Research Ethics Education Program in Jordan" and has been supported by NIH grant number (1R25TW010026-01), hosted by Jordan University of Science and Technology.

\section{Author Contributions}

All authors made a significant contribution to the work reported, whether that is in the conception, study design, execution, acquisition of data, analysis and interpretation, or in all these areas; took part in drafting, revising or critically reviewing the article; gave final approval of the version to be published; have agreed on the journal to which the article has been submitted; and agree to be accountable for all aspects of the work.

\section{Disclosure}

The authors report no conflicts of interest for this work.

\section{References}

1. Worldometer. COVID-19 coronavirus pandemic; 2020.

2. Randolph HE, Barreiro LB. Herd immunity: understanding COVID-19. Immunity. 2020;52(5):737-741. doi:10.1016/j.immuni.2020.04.012

3. Atkeson A. What Will Be the Economic Impact of Covid-19 in the Us? Rough Estimates of Disease Scenarios. National Bureau of Economic Research; 2020:0898-2937.

4. Layne SP, Hyman JM, Morens DM, Taubenberger JK. New Coronavirus Outbreak: Framing Questions for Pandemic Prevention. American Association for the Advancement of Science; 2020.

5. Nussbaumer-Streit B, Mayr V, Dobrescu AI, et al. Quarantine alone or in combination with other public health measures to control COVID-19: a rapid review. Cochrane Database Syst Rev. 2020;4.

6. Lyu W, Wehby GL. Community use of face masks and COVID-19: evidence from a natural experiment of state mandates in the US: study examines impact on COVID-19 growth rates associated with state government mandates requiring face mask use in public. Health Aff. 2020;39(8):1419-1425. doi:10.1377/hlthaff.2020.00818

7. Courtemanche C, Garuccio J, Le A, Pinkston J, Yelowitz A. Strong social distancing measures in the United States reduced the COVID-19 growth rate: study evaluates the impact of social distancing measures on the growth rate of confirmed COVID-19 cases across the United States. Health Aff. 2020;39(7):1237-1246. doi:10.1377/hlthaff.2020.00608

8. Lurie N, Saville M, Hatchett R, Halton J. Developing Covid-19 vaccines at pandemic speed. $N$ Engl J Med. 2020;382(21):1969-1973.

9. Singh K, Mehta S. The clinical development process for a novel preventive vaccine: an overview. J Postgrad Med. 2016;62(1):4-11. doi:10.4103/0022-3859.173187

10. WHO. Guidelines on Clinical Evaluation of Vaccines: Regulatory Expectations. WHO Expert Committee on Biological Standardization Fifty-Second Report. Geneva: World Health Organization; 2004:035-101.

11. DeRoo SS, Pudalov NJ, Fu LY. Planning for a COVID-19 vaccination program. JAMA. 2020.

12. Schmotzer GL. Barriers and facilitators to participation of minorities in clinical trials. Ethn Dis. 2012;22(2):226-230.

13. Detoc M, Bruel S, Frappe P, Tardy B, Botelho-Nevers E, GagneuxBrunon A. Intention to participate in a COVID-19 vaccine clinical trial and to get vaccinated against COVID-19 in France during the pandemic. Vaccine. 2020;38(45):7002-7006. doi:10.1016/j.vaccine.2020.09.041

14. Dodd RH, Cvejic E, Bonner C, Pickles K, McCaffery KJ. Willingness to vaccinate against COVID-19 in Australia. Lancet Infect Dis. 2020. doi:10.1016/S1473-3099(20)30559-4 
15. Jiang HDC, Wang Z, Wang L, et al. Exploration and application of a novel attempt to recruit participants in clinical trials of vaccines under the emergency. Zhonghua Yu Fang Yi Xue Za Zhi. 2020;54(9):963-967.

16. World Medical A. World medical association declaration of helsinki: ethical principles for medical research involving human subjects. JAMA. 2013;310(20):2191-2194. doi:10.1001/jama.2013.281053

17. WHO. Coronavirus disease (COVID-19) pandemic. World Health Organization. 2020.

18. Menzella F, Biava M, Barbieri C, Livrieri F, Facciolongo N. Pharmacological treatment of COVID-19: lights and shadows. Drugs Context. 2020;9:1-11. doi:10.7573/dic.2020-4-6

19. Xia S, Duan K, Zhang Y, et al. Effect of an inactivated vaccine against SARS-CoV-2 on safety and immunogenicity outcomes: interim analysis of 2 randomized clinical trials. JAMA. 2020;324 (10):1-10. doi:10.1001/jama.2020.15543

20. Zhu FC, Guan XH, Li YH, et al. Immunogenicity and safety of a recombinant adenovirus type-5-vectored COVID-19 vaccine in healthy adults aged 18 years or older: a randomised, double-blind, placebo-controlled, Phase 2 trial. Lancet. 2020;396(10249):479-488. doi:10.1016/S0140-6736(20)31605-6

21. Folegatti PM, Ewer KJ, Aley PK, et al. Safety and immunogenicity of the ChAdOx1 nCoV-19 vaccine against SARS-CoV-2: a preliminary report of a Phase $1 / 2$, single-blind, randomised controlled trial. Lancet. 2020;396(10249):467-478.

22. Lackland DT, Sims-Robinson C, Jones Buie JN, Voeks JH. Impact of COVID-19 on clinical research and inclusion of diverse populations. Ethn Dis. 2020;30(3):429-432. doi:10.18865/ed.30.3.429

23. Farrell R, Michie M, Pope R. Pregnant women in trials of covid-19: a critical time to consider ethical frameworks of inclusion in clinical trials. Ethics Hum Res. 2020;42(4):17-23. doi:10.1002/eahr.500060

24. AlNaamani K, AlSinani S, Barkun AN. Medical research during the COVID-19 pandemic. World J Clin Cases. 2020;8(15):3156-3163. doi:10.12998/wjcc.v8.i15.3156

25. Calina D, Hartung T, Docea AO, et al. COVID-19 vaccines: ethical framework concerning human challenge studies. Daru. 2020;1-6.
26. Eyal N, Lipsitch M, Smith PG. Human challenge studies to accelerate coronavirus vaccine licensure. J Infect Dis. 2020;221(11):1752-1756. doi:10.1093/infdis/jiaa152

27. Grady C, Shah S, Miller F, et al. So much at stake: ethical tradeoffs in accelerating SARSCoV-2 vaccine development. Vaccine. 2020;38 (41):6381-6387. doi:10.1016/j.vaccine.2020.08.017

28. Evans NG, Imperiale MJ. Human infection challenge studies: a test for the social value criterion of research ethics. mSphere. 2020;5(4):4. doi: 10.1128/mSphere.00669-20

29. Francis A, Whittemore R, Jeffery DR, Pearce LB, Roth JA. Catecholamine-metabolizing enzyme activity in the nigrostriatal system. Biochem Pharmacol. 1987;36(13):2229-2231. doi:10.1016/ 0006-2952(87)90157-2

30. Keinonen T, Keränen T, Klaukka T, Saano V, Ylitalo P, Enlund H. Investigator barriers and preferences to conduct clinical drug trials in Finland: a qualitative study. Pharm World Sci. 2003;25(6):251-259. doi:10.1023/B:PHAR.0000006517.36241.a5

31. Staniszewska A, Lubiejewska A, Czerw A, et al. Awareness and attitudes towards clinical trials among polish oncological patients who had never participated in a clinical trial. Adv Clin Exp Med. 2018;27(4):525-529. doi:10.17219/acem/68762

32. Hughson JA, Woodward-Kron R, Parker A, et al. A review of approaches to improve participation of culturally and linguistically diverse populations in clinical trials. Trials. 2016;17(1):263.

33. Friedman DB, Foster C, Bergeron CD, Tanner A, Kim SH. A qualitative study of recruitment barriers, motivators, and community-based strategies for increasing clinical trials participation among rural and urban populations. Am J Health Promot. 2015;29 (5):332-338. doi:10.4278/ajhp.130514-QUAL-247

34. Bergeron CD, Foster C, Friedman DB, Tanner A, Kim SH. Clinical trial recruitment in rural South Carolina: a comparison of investigators' perceptions and potential participant eligibility. Rural Remote Health. 2013;13(4):2567.
Patient Preference and Adherence

\section{Publish your work in this journal}

Patient Preference and Adherence is an international, peer-reviewed, open access journal that focusing on the growing importance of patient preference and adherence throughout the therapeutic continuum. Patient satisfaction, acceptability, quality of life, compliance, persistence and their role in developing new therapeutic modalities and compounds to optimize clinical outcomes for existing disease states are major areas of interest for the journal. This journal has been accepted for indexing on PubMed Central. The manuscript management system is completely online and includes a very quick and fair peer-review system, which is all easy to use. Visit http:// www.dovepress.com/testimonials.php to read real quotes from published authors. 